\title{
Aetiological factors in cutaneous malignant melanomas seen at a UK skin clinic
}

\author{
C M JANINE BELL, ${ }^{1}$ CLAIRE M JENKINSON,${ }^{2}$ TREVOR J MURRELLS, ${ }^{2}$ RICHARD \\ G SKEET, ${ }^{2}$ AND JOHN D EVERALL ${ }^{3}$ \\ From the Epidemiological Monitoring Unit, ${ }^{1}$ London School of Hygiene and Tropical Medicine, London; Thames \\ Cancer Registry, ${ }^{2}$ Sutton; and The Royal Marsden Hospital, ${ }^{3}$ London
}

SUMMARY A clinic-based case-control study was set up in 1961 to examine a variety of aetiological factors in malignant melanoma cases compared with controls with other non-malignant skin conditions. The 268 cases and 1577 controls showed odds ratios of 1.9 for red hair, 2.0 for skin that burns in the sun, and no difference between indoor and outdoor workers or between Celts and other Europeans, consistent with the results of more recent studies. Exposure to 16 specific chemicals was recorded in the study and, among these, men exposed to cutting oils were found to have a significantly raised odds ratio of 1.91 . Other statististically significant findings were an elevated risk among women diabetics, particularly in the postmenopausal age group, and a reduced risk of 0.7 among cigarette smokers.

Several large case-control studies of cutaneous malignant melanoma published since $1980^{1-8}$ have considerably advanced our knowledge of the aetiology of the disease, although the contribution to the risk from occupational factors is still uncertain, only a few studies showing evidence of an occupational risk. ${ }^{9}$ The study reported here was set up in 1961 in order to test hypotheses which were current at that time about the aetiology of melanoma. In addition to the now established risk factors, such as complexion, reaction to the sun, and sun exposure, data were collected about exposure to a variety of potential carcinogens including cutting oil and mineral oil. Cutting oils used in the engineering industry are known to cause cancer of the skin, especially of the scrotum. ${ }^{11}$ Few occupational exposure data have been collected in previous studies of melanoma, but findings from a variety of studies ${ }^{9}$ suggest that petrochemicals, polychlorinated biphenols (PCB), and ionising radiation exposure may be important.

Recent studies have consistently reported the strongest risk factors as (a) red hair, with an odds ratio in the range 2.0-5.9 compared to dark hair; (b) skin reaction to the sun (it is not yet clear whether burning, blistering, not tanning, or freckling is the most important) with risk factors of 2.0-3.5 compared to skin that tans and does not burn. This factor also seems to explain any risk associated with light skin colour. Finally, (c) the presence of naevi on the body carries a relative risk of up to 30 or higher even in
Britain. ${ }^{10}$ Sun exposure has been found to be a less important factor except in the Queensland study ${ }^{6}$ where exposure is very intense and where the higher risk estimates quoted above were obtained. Eye colour and ethnic origin (within Caucasian groups) contribute very little to the risk when the factors above have been taken into account.

\section{Methods}

Patients were eligible for the study if they had presented to the skin clinics run by the study clinician (JDE) with a new skin lesion between 1 January 1961 and 28 February 1982 . There was no restriction on age, sex or area of residence, although most patients lived in south east England. The cases were diagnosed with nodular or superficial spreading melanoma (histologically confirmed using standard histological classification through the study period). Most cases presented at the Royal Marsden Hospital (RMH). Controls were patients with non-malignant skin conditions presenting at RMH, St Thomas' Hospital or King Edward's Memorial Hospital, Ealing. All patients were entered into the study provided that a full physical examination had been performed. Most referrals were from general practitioners and some were from consultants at other hospitals.

The data were collected using a standard questionnaire, which included an assessment of complexion, sun sensitivity, sun exposure, past 
medical history, family history, and occupational exposure to 15 specific possible carcinogens. The majority of the information was collected at the first examination of the patient by the consultant or his registrars, who were all instructed in the aims of the study and the method of detailed history-taking. Examination included a top to toe examination for skin lesions of any kind. The consultant endeavoured to see all cases and controls at least once in order to ensure completeness of data collection and consistency of diagnostic criteria. The study secretary transferred the information to the questionnaire from the case-notes; she checked for inaccuracies and made good any omission by contacting the patient. In 1983 the data were transferred from the questionnaires to a computerised database for analysis using the normal error-checking procedures.

An unmatched case-control analysis was carried out using standard methods. ${ }^{12}$ The data were stratified by age using six levels (<30, 30-39, 40-49, 50-59, 60-69, $70+)$ unless zero cells occurred when strata were merged. The maximum likelihood estimate (MLE) of the odds ratio was obtained using the generalised linear interactive modelling procedure for fitting a multivariate logistic model incorporating the factor being tested, age, and year of diagnosis. The MantelHaenszel chi-square statistic was used to calculate two-sided probabilities of the observed odds ratios being different from one.

\section{Results}

There were 268 cases, 148 with superficial spreading and 120 nodular melanomas. There were 1577 controls in the same period. The controls presented with over 100 different non-malignant skin conditions, the majority ( $79 \%$ ) falling into the 17 groups shown in
Table 1 The 17 most common control conditions

\begin{tabular}{lc}
\hline Condition & $\%$ \\
\hline Basil cell papilloma & 17 \\
Actinic keratosis & 12 \\
Naevi - various & 10 \\
Warts (not pitch) & 8 \\
Eczema & 6 \\
Cysts & 3 \\
Granuloma & 3 \\
Pruritus/prurigo & 2 \\
Lichens & 2 \\
Keratoacanthoma & 2 \\
Psoriasis & 2 \\
Haemangioma & 2 \\
Tinea pedis & 2 \\
Dermatofibroma & 2 \\
Cutaneous horn & 2 \\
Acne & 2 \\
Pitch warts & 1 \\
& \\
& \\
& Total \\
\hline
\end{tabular}

table 1. Sunlight is the direct cause only of actinic keratosis and the indirect cause (through its acceleration of the ageing of the skin) of basal cell papilloma. These two groups constitute about onethird of the controls.

The cases and controls were well matched for sex distribution but the distributions of age and of year of diagnosis differed significantly between cases and controls $(p<0.001$ and $p<0.05$ respectively). Therefore, all the odds ratios are age-adjusted unless otherwise stated. The number of patients for whom information on the factor in question was missing is shown in parenthesis in the first column of the table and was low $(<10 \%)$ for most factors. The $95 \%$ confidence interval (CI) has been estimated for those factors that achieved statistical significance.

Table 2 shows the odds ratios for exposure to

Table 2 Risk factors for chemical exposures among men (110 cases, 726 controls)

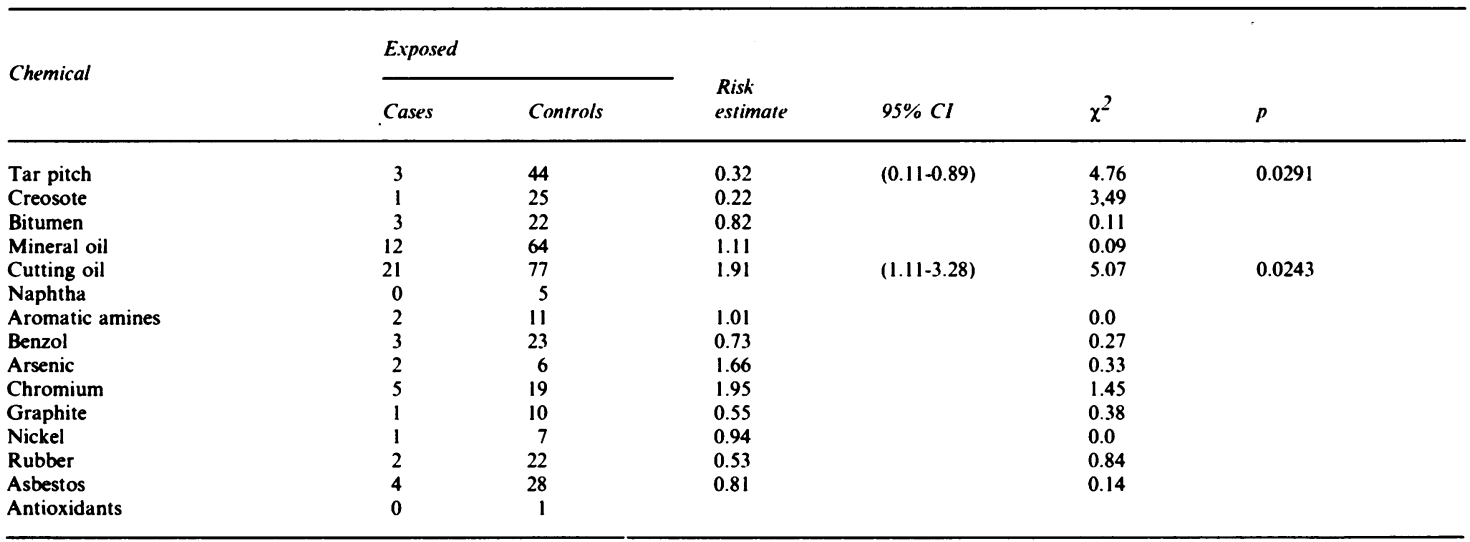

NB The sixteenth group was 'OTHER CHEMICALS.' The exposures were extremely varied in this group and no evidence of a raised risk was seen. 
various chemicals among the male patients only. Patients were asked whether they had ever been exposed to the chemicals. The numbers exposed were small except for mineral oil and cutting oil, the latter showing a significant, almost two-fold risk of melanoma. When adjusted for year of diagnosis as well as age, the risk estimate for cutting oil exposure was $2.13(p=0.02, C I=1.11-3.28)$. The lifetime occupation history and age at diagnosis of the exposed melanoma cases are shown in table 3 . The risk estimate for exposure to all the chemicals except mineral oil and cutting oil grouped together was 1.16
( $n=30$ cases, 201 controls) and, although not significant, provides a baseline for comparison with the oils.

Table 4 shows the results for factors related to complexion and sensitivity to the sun. All these factors were associated with raised risks of melanoma very similar to those reported by other studies. In contrast, sun exposure indices (table 5) were not associated with melanoma, except for tropical residence. Patients were recorded as positive for these factors only if they had had maximal sun exposure, that is, "frequent sunbathing" meant sunbathing at every available

Table 3 Cutting oil exposed melanomas (male)

\begin{tabular}{|c|c|}
\hline Occupation & $\begin{array}{c}\text { Age at } \\
\text { diagnosis }\end{array}$ \\
\hline Engineer & 31 \\
\hline Labourer - building sites - fitter & 28 \\
\hline Bench fitter - engineer & 58 \\
\hline Director engineering company & 46 \\
\hline Army - tanks : milk roundsman : car mechanic & 61 \\
\hline Fitter's mate : typewriter mechanic : wireless mechanic & 56 \\
\hline Metal stockist - designer machine tools & 52 \\
\hline Cabinet maker ( 3 years) : plastics turner $(10$ years) $: \quad$ engineer & 70 \\
\hline Baker - engineer & 61 \\
\hline Cable ganger (LEB) : hod carrier : maintenance - Plessey's - sewage pump house & 74 \\
\hline Merchant navy : amateur sailor : swimming instructor : salesman & 56 \\
\hline Marketing manager & 36 \\
\hline Electrician - maintenance foreman & 61 \\
\hline RAF : machine slotter & 59 \\
\hline Cable engineer : electrician ( 5 years), cable and wireless ( 16 years) & 37 \\
\hline Maintenance in light engineering/welder & 32 \\
\hline Project engineer - machine fitter & 57 \\
\hline Factory work (1 year) : banker & 58 \\
\hline Motor fitter & 22 \\
\hline
\end{tabular}

Table 4 Complexion: 268 cases, 1577 controls, both sexes

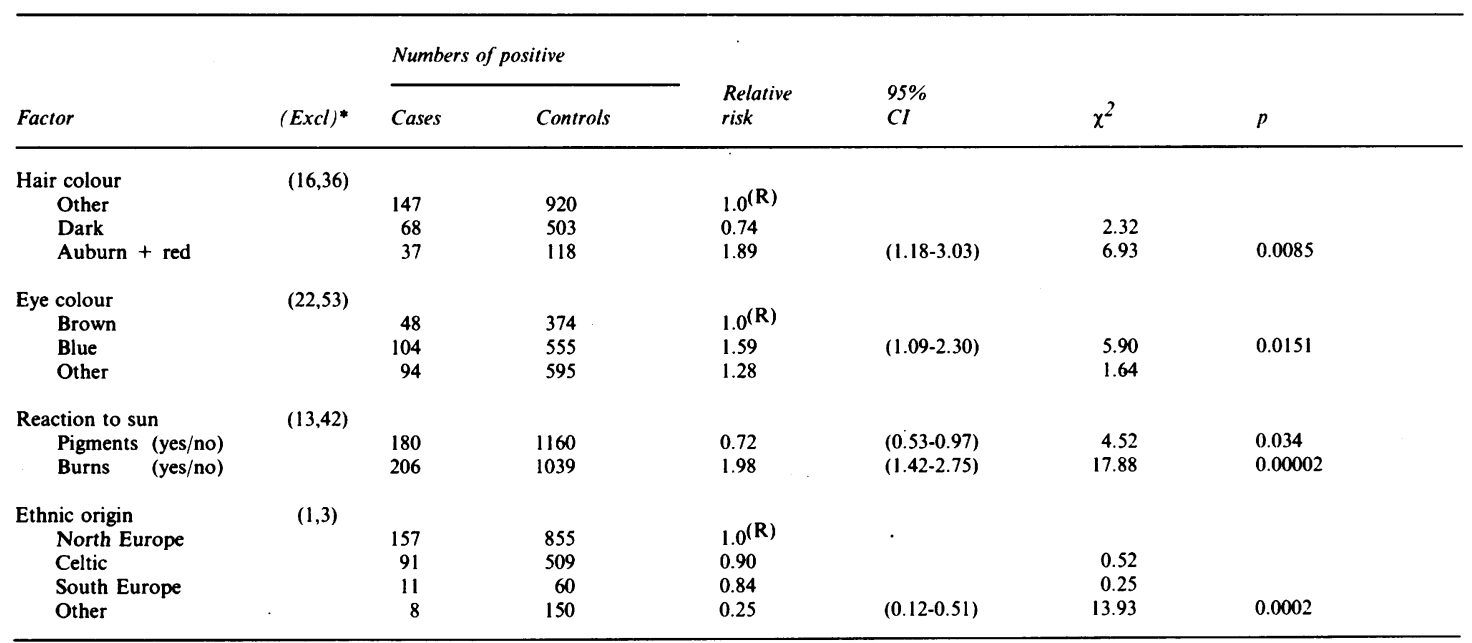

* Excluded (cases, controls) due to missing information

(R) Excluded (cases, con 
Table 5 Sun exposure: men and women: 268 melanomas, 1577 controls

\begin{tabular}{|c|c|c|c|c|c|c|c|}
\hline \multirow[b]{2}{*}{ Factor } & \multirow[b]{2}{*}{$(E x c l)^{*}$} & \multicolumn{2}{|c|}{ Exposed numbers } & \multirow{2}{*}{$\begin{array}{l}\text { Relative } \\
\text { risk }\end{array}$} & \multirow{2}{*}{$\begin{array}{l}95 \% \\
C I\end{array}$} & \multirow[b]{2}{*}{$\chi^{2}$} & \multirow[b]{2}{*}{$p$} \\
\hline & & Cases & Controls & & & & \\
\hline Frequent sunbathing & $(7.20)$ & 124 & 755 & 0.84 & & 1.63 & \\
\hline $\begin{array}{l}\text { Occupation: } \\
\text { Indoor }\end{array}$ & $(1,0)$ & 207 & 1212 & $1.0^{(\mathrm{R})}$ & & & \\
\hline Indoor and outdoor & & 43 & 280 & 0.94 & & 0.12 & \\
\hline Outdoor & & 17 & 85 & 1.31 & & 0.91 & \\
\hline Keen gardener & & 54 & 327 & 1.02 & & 0.02 & \\
\hline Outdoor sportsman & & 60 & 353 & 1.00 & & 0.0 & \\
\hline $\begin{array}{l}\text { Area born } \\
\text { City }\end{array}$ & $(5,1)$ & & & & & & \\
\hline $\begin{array}{l}\text { City } \\
\text { Country }\end{array}$ & & 153 & 1006 & $1.0^{(\mathrm{R})}$ & & & \\
\hline $\begin{array}{l}\text { Country } \\
\text { Seaside }\end{array}$ & & 80 & 427 & 1.19 & & 1.32 & \\
\hline Seaside & & 30 & 143 & 1.32 & & 1.53 & \\
\hline $\begin{array}{l}\text { Tropical residence } \\
\text { Never }\end{array}$ & $(2,18)$ & & & & & & \\
\hline $\begin{array}{l}\text { Never } \\
\text { Subtropical }\end{array}$ & & 197 & 971 & $1.0^{(R)}$ & & & \\
\hline $\begin{array}{l}\text { Subtropical } \\
\text { Sub and tropical }\end{array}$ & & $\begin{array}{l}33 \\
17\end{array}$ & $\begin{array}{l}199 \\
124\end{array}$ & $\begin{array}{l}0.77 \\
0.65\end{array}$ & & $\begin{array}{l}2.07 \\
2.41\end{array}$ & \\
\hline Tropical & & 12 & 123 & 0.45 & $(0.24-0.83)$ & 6.43 & 0.0112 \\
\hline $\begin{array}{l}1-4 \text { years } \\
5+\text { years }\end{array}$ & & 21 & 206 & $1.0^{(R)}$ & & & \\
\hline $5+$ years & & 41 & 240 & 1.80 & $(1.01-3.20)$ & 4.18 & 0.0409 \\
\hline
\end{tabular}

(R) The number of (cases, controls) excluded due to missing data item.
Reference group.

opportunity, not only on holiday; "keen gardener" or "outdoor sportsman" meant the pursuit of the hobby most weekends throughout the season. None of these factors showed an excess risk. Residence in the tropics, however, was more common among controls than cases, giving an anomalous result with an apparent significant protective effect for melanoma. The definition of tropical or subtropical was arrived at using a reference list of countries together with the patient's own knowledge of the continent in which he or she had lived. The proportion of the population with tropical residence was high at more than $25 \%$, but we have no figures for a comparable group drawn from the general population. All patients of nonEuropean ethnic origin were excluded from the analysis. The duration of residence in years was recorded (less than one year not being counted) and age at first tropical residence. The majority of patients $(62 \%)$ who had lived in the (sub) tropics had long durations of five or more years, and two-thirds were first exposed as children (age 0-14). Adults mainly stayed for short durations (eg, in the armed forces). So large a fraction ( $40 \%)$ had young exposure with long duration that these two factors were strongly confounded. However, there was evidence of a doseresponse relation for melanoma with increasing duration of residence in the tropics, residence of five or more years carrying almost twice the risk of shorter durations. The low overall odds ratio for melanoma appears to be due to the effect of intense sunlight on the control conditions, although there was no evidence that conditions such as actinic keratosis or basal cell papilloma were more frequent among controls with tropical residence than among those without.

Table 6 shows the results for various other factors. A significantly lower risk of melanoma was observed in smokers. A raised risk was observed in diabetics. Although this was based on small numbers it seemed worthy of further investigation. The raised risk was present only in women $(R R=3.72, n=10, p=0.002$, $\mathrm{CI}=1.64-8.45)$. However, examination of the hospital notes for the 10 female diabetic melanomas showed that four of them were diagnosed as diabetic after presentation (three at recurrence or relapse) and these were recoded as non-diabetic at presentation. Thus six female diabetic melanomas remained, four of which were diagnosed at least two years prior to presentation and two at presentation. It is common for matureonset diabetes to be diagnosed at presentation to hospital for an unrelated condition; all cases and controls were given glucose tolerance tests if indicated at presentation. The final risk estimate, adjusted for both age and year of diagnosis, was 2.18 and was significant only in the postmenopausal women aged over $50(R R=4.13, n=5, p=0.02, C I=1.34-12.69)$.

Very few patients recorded a positive family history (table 6) of psoriasis, eczema, migraine or hay fever. A family history of skin trouble, diabetes, and cancer was more common, only the latter showing a significant result which may well reflect recall bias. 
Table 6 Other possible risk factors: Men and women: 268 melanomas, 1577 controls

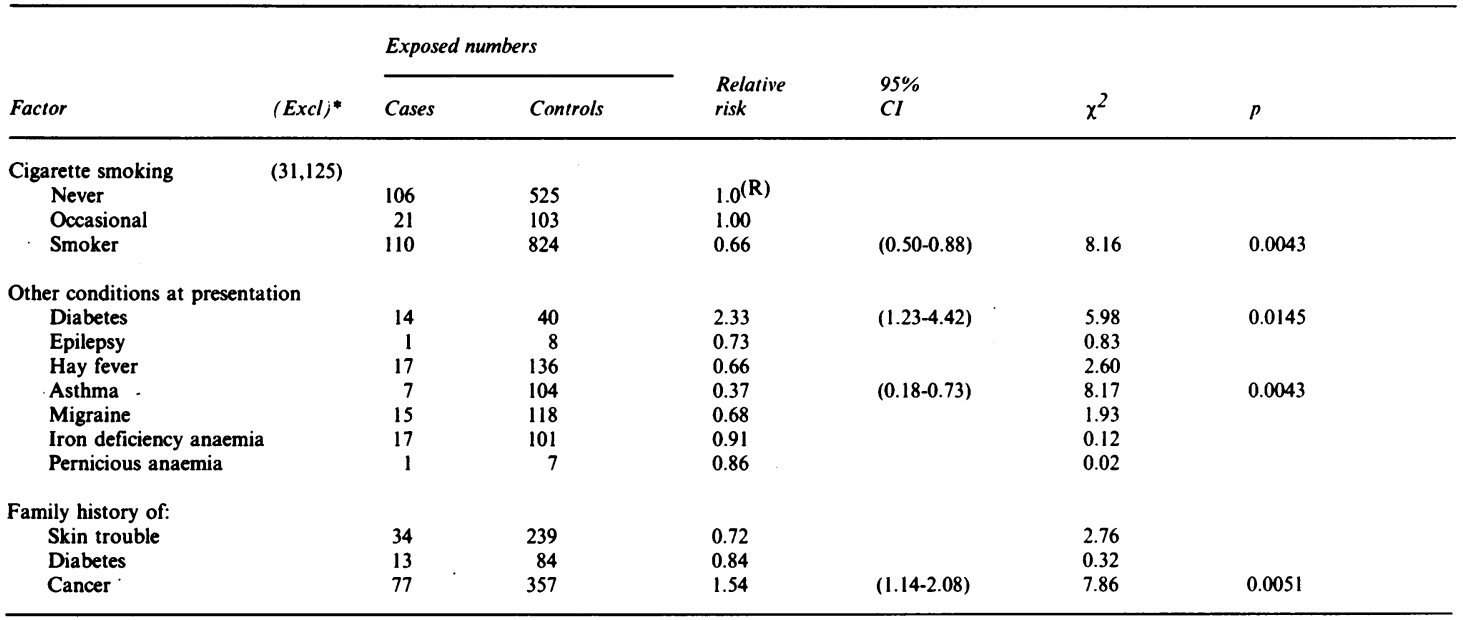

(R) Number of (cases and controls) excluded due to missing data item.

(R) Reference group.

\section{Discussion}

\section{POTENTIAL BIASES}

The use of cases and controls drawn from a particular clinic is almost certain to lead to some selection bias. Among the melanoma cases there were more of the nodular type (45\% compared with $20 \%$ incident in the population), presumably because of the more serious nature of this histological type; and there were fewer female cases (59\% compared with $65-70 \%$ in the UK). Such case-selection may bias the risk estimate up or down but will not produce spurious evidence of risk where none exists. There seemed to be no reason to exclude controls drawn from the cancer hospital (RMH), as few had other malignancies and their skin conditions were typical of the controls as a whole. There was little evidence of social class bias, although melanoma incidence nationally is higher among the higher social classes. The percentage distribution of social classes I to V, based on occupation, was 15,34 , $14,26,9$, and $2 \%$ respectively among our male cases, and $8,31,14,30,14$, and $4 \%$ for England and Wales as a whole. ${ }^{13}$

The interviewers in this study were not blind to case-control status, but the large numbers of hypotheses under test, the long study period, and the fact that an identical questionnaire was in use not only for melanomas and controls but also for all patients with squamous cell carcinoma or basal cell carcinoma lesions of the skin should minimise the bias.

The controls were not ideal as some non-malignant skin conditions have sun-related aetiology in common with melanoma, while the aetiology of many other conditions is unknown. However, major biases seem unlikely since the results for the well established risk factors (red hair, pigmentation) were so close to those reported by other workers. ${ }^{1-8}$

The results tables represent all the data collected in the study (with the exception of some data items collected as free text). Because some $\mathbf{3 5}$ associations were tested, there is a possibility of one or two false positive results at a $5 \%$ level of significance. The interesting findings discussed below can only be judged in the light of future evidence.

\section{DIABETES}

Clinical suspicions of a link between diabetes and melanoma prognosis did increase over the study period, hence melanoma cases may have been more likely to have been investigated for diabetes. However, the lack of risk in men in the same period argues against there being a strong bias in the detection of diabetes. While the number of cases in this study is very small, the result is consistent with recently published findings. O'Mara et al ${ }^{14}$ noted that their large study of diabetes was the first to show a raised risk of melanoma and non-melanoma skin cancer (only the latter being statistically significant) in female diabetics. They suspected an ascertainment bias. The relative rarity of melanoma may have prevented the detection of raised risks in previous cohort studies, particularly if the risk were confined to women in the postmenopausal age group. While the age-specific incidence rates for mature-onset diabetes and melanoma are very different, the former increasing with age and the latter being most common at about 40 
years of age, oestrogen may well play a role in both diseases. $^{8,15-18}$

CUTTING OIL

Cutting oil is a widely used metal-working lubricant or coolant. Exposure to this oil is strongly associated with squamous cell carcinoma of the skin, especially of the scrotum, ${ }^{11,19}$ but has not previously been linked with melanoma.

Most types of cutting oil contain at least $5 \%$ mineral oil, which is not necessarily highly refined and contains polynuclear aromatic hydrocarbons (PAH) including benzo(a)pyrene. PAH levels were significantly higher a decade ago than they are today. Cutting oils also contain many additives to give them the desired properties such as emulsifiers, anti-rust, and antibacterial agents. $\mathrm{N}$-nitrosamines formed from these additives have been detected in cutting oils, particularly after use. The excesses of bladder cancer found in metal workers have been attributed to these aromatic amines. Animal evidence suggests that a fraction of such ingested oils is incorporated into body lipids, skin effects including lipid granuloma and melanosis. ${ }^{19}$ A melanoma excess has been reported in several cohort studies of oil refinery workers. ${ }^{9}$ A large study of eight UK oil refineries ${ }^{20}$ followed up more than 34000 men employed over a 25-year period. Owing to the relative rarity of melanoma, only 14 cases were observed in this study, an almost twofold (and unexplained) excess.

\section{CIGARETTE SMOKING}

A low risk among smokers was also found by Green, ${ }^{21}$ particularly among women. In our data, both sexes showed a reduced risk, but it was significant only among women. The result seems unlikely to be due to social class bias. The number of controls who had a smoking-related cancer (of lung or oesophagus) was less than $2 \%$, which is negligible compared with the $34 \%$ deficit in the melanoma risk. The result could be due to some other association between the control conditions and smoking.

We are grateful to the Emmanjay Trust for their contribution to the study and to the Health and Safety Executive for funding CMJ. We are indebted to Mrs J Reide for her tireless pursuit of perfection in the collection of data. We thank Mrs B Howard for entering the data into the computer with such accuracy and Miss J Duncanson for typing the manuscript.

\section{References}

${ }^{1}$ Holman CDJ, Armstrong BK. Pigmentary traits, ethnic origin, benign naevi and family history as risk factors for cutaneous malignant melanoma. J Natl Cancer Inst 1984; 72: 257-66.

2 Beral V, Evans S, Shaw H, Milton G. Cutaneous factors related to the risk of malignant melanoma. Br J Dermatol 1983; 109: 165-72.

${ }^{3}$ Beral V, Evans S, Shaw H, Milton G. Malignant melanoma and exposure to fluorescent lighting at work. Lancet 1982; 2: 290-3.

${ }^{4}$ Elwood JM, Gallagher RP, Hill GB, Spinelli JJ, Pearson JCG, Threlfall W. Pigmentation and skin reaction to sun as risk factors for cutaneous melanoma: Western Canada Melanoma Study. Br Med J 1984; 288: 99-102.

5 Elwood JM, Gallagher RP, Davison J, Hill GB. Sunburn, suntan and the risk of cutaneous malignant melanoma Western Canada Melanoma Study. Br J Cancer 1985; 51: 543-9.

${ }^{6}$ Green A, Siskind V, Bain C, Alexander J. Sunburn and malignant melanoma. Br J Cancer 1985; 51: 393-7.

${ }^{7}$ Green A, Maclennan R, Siskind V. Common acquired naevi and the risk of malignant melanoma. Int $J$ Cancer 1985; 35: 297-300.

${ }^{8}$ Gallagher RP. (ed). Epidemiology of malignant melanoma. Recent Results in Cancer Research 1986; 102.

${ }^{9}$ Austin DF, Reynolds P. Occupation and malignant melanoma of the skin. In Recent Results in Cancer Research 1986; 102: 98-107.

${ }^{10}$ Swerdlow AJ, English J, Mackie RM, et al. Benign melanocytic naevi as a risk factor for malignant melanoma. Br Med J 1986; 292: 1555-9.

${ }^{11}$ Kipling MD, Waldron HA. Polycyclic aromatic hydrocarbons in mineral oil, tar and pitch, excluding petroleum pitch. Prev Med 1976; 5: 262-78.

12 Breslow NE, Day NE. Statistical methods in cancer research, Vol. 1 The Analysis of Case-control studies. Int. Agency Res. Cancer 1980. Lyon.

13 OPCS. Occupational Mortality, The Registrar General's Supplement for England and Wales, 1970-72. HMSO Series DS, no. 1, London. 1978.

${ }^{14}$ O.Mara BA, Byers T, Schoenfield E. Diabetes mellitus and cancer risk: A multisite case-control study. J Chron Dis 1985; 38: 435-41.

${ }^{15}$ Steel JM, Duncan LJP. Serious complications of oral contraception in insulin-dependent diabetics. Contraception 1978; 17: 291-5.

${ }^{16}$ Beral V, Evans S, Shaw H, Milton G. Oral contraceptive use and malignant melanoma in Australia. $\mathrm{Br} J$ Cancer 1984; 50: 681-5.

${ }^{17}$ Holman CDJ, Armstrong BK, Heenan PJ. Cutaneous malignant melanoma in women: Exogenous sex hormones and reproductive factors. Br J Cancer 1984; 50: 673-80.

18 Gallagher RP, Elwood JM, Hill GB, Coldman AJ, Threlfall WJ, Spinelli JJ. Reproductive factors, oral contraceptives and risk of malignant melanoma: Western Canadian Study. Br J Cancer 1985; 52: 901-7.

${ }^{19}$ Mineral oils. In: Evaluation of the carcinogenic risk of chemicals to humans. IARC Monogr Lyons 1984; vol 33: 87-167.

${ }^{20}$ Rushton L, Alderson MR. An epidemiological survey of eight oil refineries in Britain. Br J Ind Med 1981; 38: 225-34.

${ }^{21}$ Green A, Bain C, McLennan R, Siskind V. Risk factors for cutaneous melanoma in Queensland. In Recent Results in Cancer Research 1986; 102: 76-97. 